Bol. Acad. peru. leng. 61. 2016 (47-67)

\title{
Forjar una forma poética: Estancias de Javier Sologuren
}

\section{Forge a poetic form: Estancias by Javier Sologuren}

\author{
Renato Guizado YamPI \\ Pontificia Universidad Católica del Perú
}

\section{Resumen:}

En este artículo me propongo estudiar la estancia de Javier Sologuren como una forma poética precisa, un cúmulo de rasgos que todos los poemas del conjunto Estancias (1960), han de compartir. Para ello, perfilaremos una definición descriptiva que nos permita reconocer una forma poética en la estancia, junto con la innovación estructural que esta supone, identificando constantes estilísticas, que en un contexto comparativo servirían como elementos diferenciales, a partir de manifestaciones objetivas.

\section{Abstract:}

This article attempts to study the Estancia by Javier Sologuren, as an accurately poetic form which contains a cluster of features shared by all the poems in this collection. In order to do so, we outline a descriptive definition that allows us to recognize a poetic form in the Estancia, along with a structural innovation, 
identifying stylistic patterns, which would serve as differential elements from objective demonstrations, in a comparative context.

Palabras clave: Javier Sologuren, poesía, estancia, constantes estilísticas.

Keywords: Javier Sologuren, poetry, estancia, stylistic patterns.

Recibido: 31/01/2016

Aceptado: 29/02/2016

\begin{abstract}
$Y$ este amor por las formas
más pequeñas por los rostros en la espuma y el mar sobre mi pecho.
\end{abstract}

A Bella Brusso en su cumpleaños

Tal como permite pensar la flexión plural de su título, Estancias (1960), de Javier Sologuren, es un conjunto conformado por veintidós poemas. Entiéndase esta aclaración no como notoria obviedad sino como una postura que se formula a partir de la opinión contraria. $Y$ es que no falta quien interpreta los versos que nos conciernen como un solo cuerpo, del cual cada uno de los poemas es un miembro que compone una estructura final, estructura unitaria dividida. Sin embargo, las razones para creerlo así, bien podrían parecer fundamentadas en el texto. En principio, la idea se sostiene en la observación de la tipografía: todos los poemas reciben una numeración cardinal perfectamente capaz de tener su correlato ordinal; se diría entonces que la 
indicación numérica es muestra de un deseo del autor de aclarar la división y el ordenamiento de su trabajo. Por otro lado, el análisis métrico, sumado a la acotación etimológica respecto del título, llevaría al lector a pensar que, efectivamente, la numeración divide y distribuye las estrofas de un poema. Es verdad que «estancia» es un vocablo que designa una estrofa italiana casi fija heredada de la tradición petrarquista; así como también es verdad que cada uno de los conjuntos separados por la numeración de Estancias son lo suficientemente cortos y sintácticamente cerrados para confundirse con tales estrofas. Por tanto, es de importancia capital la discusión acerca de si el título designa un compendio de unidades o una unidad seccionada, porque de la aclaración resultante dependerá no solo la comprensión del significado de la obra y el goce estético, sino, en el caso particular de Estancias, el conocimiento y valoración del carácter creativo de su autor.

Urge, entonces, advertir que la necesidad de hallar sofisticaciones arquitectónicas en los poemarios es una tendencia relativamente actual de la crítica peruana de poesía lírica, nacida, al parecer, de una comprensión fallida del arte de Les fleurs du mal (1857) de Charles Baudelaire y de las reflexiones que respecto de la idea de «libro» se plantea Stéphane Mallarmé en sus Divagations (1897). Esta costumbre resulta nociva tanto para la valoración de los poetas consagrados como para quienes incursionan recién en la exploración del lenguaje como medio expresivo. Sucede que, en su no siempre justificada búsqueda de 
inteligentes relaciones intertextuales de significado, la crítica enfoca sus esfuerzos solo en observaciones de conjunto, mermando y negando de facto el carácter independiente y unitario del poema en tanto que obra literaria en sí mismo, por breve que esta resulte. El poema, entonces, deja de ser la materia de estudio y sus estructuras intrínsecas son cada vez menos dilucidadas en pro de hipótesis universalizantes que, al no fundamentarse en el análisis minucioso, devienen en arbitrarias. ¡Qué actitud más alejada la de Sologuren; poeta de los haikus, de las formas pequeñas y delicadas, del detalle! Una lectura detenida de los veintidós grupos de versos de Estancias conduce a la conclusión de que la hipótesis del cuerpo único es inconcebible, ya que no existe una secuencia temática objetiva que ordene los poemas: no se evidencia progresión narrativa alguna; así como tampoco reiteraciones, ciclos o referencias intertextuales. Solo en una ocasión se presencia una proximidad temática entre los poemas 15, 16 y 17, que tratan del agua, el río y la sed, respectivamente. Sin embargo, tal coincidencia no es funcional: el orden de aparición de los poemas podría variar sin mayor problema para la comprensión y el efecto. Esto se debe a que cada grupo numerado de versos en Estancias es un poema con su propio sentido y gusto. Al respecto, nótese la clara independencia que poseen a pesar de su corta extensión: variaciones de tono, diferentes niveles y maneras de interacción sujeto-objeto, asuntos distintos y sin ecos intertextuales, expresados y agotados en estructuras cerradas y de esquemas tan variados que pueden ser 
bien conjuntos de oraciones que forman o un período, como bien una sola oración e incluso la exclamación de una frase nominal sin verbo principal. Se desmiente en ellos toda impresión de hallarse frente a algo que deba completarse; pues por más que se aborde un solo punto, a modo de vistazo, del fenómeno que capta la voz, este se construye de manera tal que se ve culminado en los detalles:
Bajo tus arcos delgados, blanca eres, Mañana, blanca frente del día.
Es tu pecho la espuma donde se baña un pájaro, y en tu vientre ligero caen las flores en ramos.

(Sologuren 2004: 148)

Por ejemplo, el poema reproducido desarrolla la idea de la blancura de la mañana en un conjunto de tres oraciones que presentan las distintas formas en que se percibe lo blanco, con la minucia, extensión y complejidad que le permiten los complementos adyacentes al verbo.

Pese a esto, si bien se afirma que cada sección numerada de versos es una obra acabada en sí misma, no hay duda de que existe un tipo de unidad perceptible del cual participa cada individuo del conjunto. Es inevitable dar por hecho que al componer estos poemas Sologuren, profesor universitario y traductor de Petrarca y otros tantos autores italianos, tenía presente la idea de la stanza como estrofa destinada a 
integrar un todo mayor; no obstante, y en vista de los resultados obtenidos en el análisis, es poco plausible sostener que la relación propuesta entre la estrofa italiana y las secciones de versos sea del todo análoga. La pauta se encuentra, paradójicamente, en el título mismo: la flexión de plural de un nombre designa una serie de objetos independientes con rasgos en común. El título comunica que el poeta es consciente de las coincidencias sobre las que ha estructurado sus poemas: se alude a una unidad que debe buscarse en la esencia estructural de cada poema comprendido como ente individual y no como fragmento (Silva-Santisteban 2004: 383). La estancia surge entonces como una forma poética precisa, un cúmulo de rasgos que todos los poemas del conjunto han de compartir, una unidad arquetípica que se realiza y actualiza de veintidós maneras distintas. Para perfilar una definición descriptiva que nos permita reconocer una forma poética en la estancia, junto con la innovación estructural que esta supone, es menester identificar constantes estilísticas, que en un contexto comparativo servirían como elementos diferenciales, a partir de manifestaciones objetivas.

Al no poder establecerse una norma precisa en cuanto al tiempo o la intensidad, excepto por el carácter no estrófico de los veintidós poemas, la estancia presenta un perfil inexacto desde la perspectiva del estrato sonoro, aunque sí se esboza cierto patrón de semejanzas. En primer lugar, no se sigue un esquema fijo en la cantidad de versos que componen la estancia: el rango comprende de cinco a dieciséis versos por 
composición. No obstante, se observan tendencias en este aspecto: hay seis estancias de siete versos, y cinco de ocho; mientras que la diferencia en la cantidad de versos de los poemas en general es relativamente baja: se trata de composiciones cortas en todos los casos. Otro tanto se evidencia respecto de las medidas silábicas empleadas. No solo los metros suelen variar de estancia en estancia, sino que, haciendo la salvedad de las estancias 7, 9, 11, 13, 14, 16 y 19, construidas totalmente en heptasílabos, estas presentan estructuras no isométricas cuya regularidad fluctúa entre la isometría apenas frustrada (10 y 21) y el verso relativamente libre (18 y 20). La constante en este nivel solo se halla en la proximidad de los números diferentes, ya que no en medidas exactas: las estancias no contienen versos largos ni con cesura obligada; son en su mayoría versos de arte menor, donde el endecasílabo es la mayor longitud registrada y la menos recurrente.

El carácter breve de la estancia esbozado en su ritmo de duración se confirma al observar la composición sintáctica. A saber, la estancia es una forma breve puesto que consiste en un conjunto de pocas oraciones, cuando no de una sola:

Tocándolo tan solo
con invisible rayo,
(al desnudo durmiente
bajo signo ignorado)
lo despiertas, oh Música,
para extático alzarlo
al intangible coro
donde es tu imperio exacto.

(Sologuren 2004: 150) 
Pero la particularidad de su extensión no es sinónimo de vacuidad o de nula intensidad; pues si bien el asunto de la estancia desarrolla una parte del objeto que trata, Sologuren apuesta por la condensación: el rasgo presentado se profundiza mediante detalles por medio de dos procedimientos sintácticos de dependencia que suceden en los poemas de manera separada o combinada. El primero de estos es la subordinación: se expande la oración simple aumentando los elementos adyacentes del verbo y del sujeto. En el poema anterior, el actuar de la «Música» se mostraría incompleto y con menos riqueza semántica si no fuera por el objeto indirecto y los complementos del predicado, que incluso presentan una oración subordinada. El efecto logrado es el del movimiento de una flor al abrirse, como si las experiencias mínimas de los poemas mostrasen progresivamente su verdadera amplitud y multiplicasen la sensación, emanando su sentido real. Así, a la impresión sencilla se le suma información que le da el matiz de lo trascendente al punto de tornarse en la esencia del cuerpo sentido. Sintácticamente, entonces, la estancia suele ser una composición que tiende tanto a la subordinación de oraciones como a la profusión de complementos. La condensación en la subordinación se genera al agrupar la información, ya que todos los pormenores se concentran en una misma estructura sintáctica y en torno del mismo núcleo gramatical, trabando íntimas relaciones de dependencia entre estos que no se darían si la información se repartiese en oraciones sueltas. La estancia, así, se construye sobre un esquema atómico donde el núcleo es el rasgo que el asunto del poema elabora y los electrones los detalles que se expresan en los 
elementos subordinados de la oración. Pero este ordenamiento atómico se evidencia también en los nexos no subordinantes: el segundo procedimiento de la estancia consiste en coordinar o yuxtaponer oraciones procurando la mayor dependencia de sentido posible entre estas, lo que deviene en una perceptible concentración de oraciones que giran en torno del mismo centro. En el caso de la estancia 12, de composición paratáctica, esta atomicidad se logra, como en otras estancias, por la reiteración del «Antiguo» como sujeto de casi todas las oraciones y por la elipsis que las hace referencialmente dependientes.

El Antiguo habla en mí.

En mí despierta.

Sus ojos son un agua cineraria.

Un pálido nenúfar, su sonrisa.

El Antiguo creyó saber,

y su creencia fue sabiduría.

Dobló la cabeza en el amor:

espuma es hoy blanquísima.

(Sologuren 2004: 150)

En segunda instancia, es posible esbozar la esencia estructural de la estancia partiendo del análisis de las peculiaridades sintácticas que, paradójicamente, distinguen a ciertos poemas del resto. Tal sucede con la estancia 17:

Tu llamarada, Sed, en el desierto estalla, en el mar, en la arena, como tu condición solitaria. 
Y sin embargo, tú,

dándole vuelta entera

al cuerpo de los hombres

en pueblos y ciudades

donde no se hallan solos,

Hambre.

(Sologuren 2004: 153)

Donde el «sin embargo» carece de un claro sentido adversativo. $\mathrm{O}$ en la estancia 10:

\author{
¡Las voces que nacen de este \\ júbilo, Primavera, \\ los vientecillos frescos \\ oreándote el cabello; \\ las vaporosas, rosadas \\ guirnaldas que te envuelven, \\ y ese licor que viertes \\ sonriéndome en la sangre!
}

(Sologuren 2004: 149)

Cuya estructura enumerativa no llega a establecer una oración completa. Es en estos casos que se evidencia con mayor nitidez lo que la estancia en tanto que forma busca transmitir: una voz que, en su emoción, expresa lo experimentado, dejando de lado la precisión lógica del discurso si es necesario. De tal manera, el poema anterior no presenta una estructura entera, pero comunica un desborde emotivo frente a las manifestaciones de la «Primavera» que encuentra la expresión adecuada de su intensidad en esa ausencia que da la impresión de potencia contenida que genera aquello que no se termina de decir. 
Asimismo, las elisiones del verbo en la estancia 19 producen un giro de calidez coloquial congruente con el tema de la amistad:

¡Qué sabor en el pan, qué fáciles los pasos, qué llevadero todo sabiéndote a mi lado, Amistad, cuánto gozo en tu apretón de manos!

(Sologuren 2004: 154)

La expresión de un estado anímico es otro rasgo capital de la estancia: la voz se muestra afectada por entidades externas; realidades que generan al interior del yo el sentimiento de lo maravilloso. Estas características también alcanzan a todos los miembros del conjunto: lo externo del yo y la maravilla. Es menester anotar, por lo tanto, que cada una de las estancias tiene como tema una entidad (dos en el caso de los poemas 14 y 17) perteneciente al ámbito de la experiencia vital. Todas las entidades se ven personificadas, salvo en la estancia 22, por el uso del vocativo y la segunda persona gramatical en la conjugación de los verbos y los pronombres; frente a estas, la voz enuncia distintas formas de exaltación: es decir, un estado de ánimo que tiene su génesis en la vivencia de las características de lo exterior. En estos rasgos encuentra mayor explicación el proceso estilístico de la condensación sintáctica: el yo lírico muestra su entusiasmo por lo que presencia al considerar indispensable la enunciación de detalles, que, además, presentan lo que hace 
grandiosas a las entidades que moldean. Por otro lado, la exaltación también sucede en el estrato rítmico de los poemas, lo que se hace patente tanto en el uso de la exclamación como en la versificación de la estructura sintáctica: la segmentación en versos de medida corta supone dividir una construcción sintáctica en sus partes mínimas, lo que deviene, debido a la pausa versal y los perceptibles encabalgamientos, en un importante énfasis sonoro para aquellas palabras que pierden protagonismo al estar subordinadas. Así, todo en la oración cobra la fuerza que produce lo maravilloso en el yo. Este efecto de realce rítmico por la pausa es conocido por Sologuren; así lo demuestra en el comentario que hace a su versión de los poemas de Mitad de la vida de Friedrich Hölderlin (Sologuren 2005: 145-146). La estancia 21 es el ejemplo más interesante de dicho procedimiento, pues llega a separar los sustantivos de sus respectivos complementos directos:
Hollado Otoño, sin la niebla de tus seres errabundos, tu cabeza cenicienta va girando tal un pomo de ungüento en las manos confidentes de un enfermo.

(Sologuren 2004: 155) 
En los mencionados atributos de la estancia se hace manifiesta la indudable relación con una forma ya existente y de gran tradición: el himno, que tiene su origen en el nacimiento mismo de la lírica occidental.

$Y$ es que se corresponde con el himno en tanto que forma en la cual el yo lírico exalta una entidad externa y que, además, presenta otras coincidencias tales como el apóstrofe lírico o el uso de temas de por sí trascendentes (la muerte, la amistad, etc.); pero la estancia posee ciertas propiedades que marcan una distancia entre Sologuren y la tradición hímnica clásica, distancia que reside en el grado de subjetividad con que el yo conceptualiza su experiencia, su huella personal. Sucede que, en principio, tanto en los himnos homéricos como en los epinicios de Baquílides o los de Píndaro, el yo lírico presenta una posición exclusivamente contemplativa frente al personaje loado, siendo el dios o el héroe el único capaz de actuar y la voz pura espectadora de lo grandioso, que nunca partícipe. De tal modo, los himnos clásicos narran los eventos que son motivo de alabanza entre otros hechos biográficos del personaje, todos lejanos de la dimensión del enunciante. Sobre la misma reflexión, Wolfgang Kayser observa de los himnos homéricos que «se expresan en la actitud de la enunciación, e incluso se puede afirmar con razón que, en el fondo, son poemas épicos, a causa de su carácter descriptivo de la objetividad, de su actitud narrativa» (1961: 447); o sea que no se muestra una estrecha compenetración entre sujeto y objeto. El tono solemne en sí mismo tiende a distanciar ambas orillas. En cambio, la compenetración es real en las 
Estancias: la intimidad entre el enunciante y su objeto cantado es mucho mayor, al punto que el yo poético puede llegar a constituirse en el ente que hace sobre la entidad loada:

Tú transitas los caminos

de mi corazón, Noche, y yo asciendo por tus venas como alborada frágil;

(Sologuren 2004: 145)

Aunque, ciertamente, es más común que el yo se presente como un sujeto pasivo de la grandiosa acción de lo externo e incluso la voz canta para seres que son parte de sí:

Por ti, Gerardo, y por ti, Claudio,

hijos míos,

vuelvo a ser lo que fui,

canta en mi corazón una canción nueva

una vieja canción que desoí.

(Sologuren 2004: 153)

En Estancias, la interacción entre la primera y la segunda persona gramatical es capaz de modificar la naturaleza de las cosas; aun la sola contemplación muestra tal intensidad que irradia la cercanía de los cuerpos en lo sensorial y plástico de la expresión que crea la apariencia de observación impresionista, espontánea; y en el movimiento activo de las cosas:

La Vid lanza sus garfios al deslumbrante cielo. 
Cálidos como labios

se aprietan los racimos

a orillas del celeste

cuerpo mediterráneo.

(Sologuren 2004: 151)

Una segunda diferencia también tiene su origen en el rasgo épico del himno clásico, y es la tendencia a la totalidad en contraste con lo fragmentario de la percepción en la estancia. El lírico griego hace de su sujeto de alabanza una totalidad uniforme en primer plano: todas las dimensiones de su existencia son dignas de loa y deben presentarse en el himno para que la exaltación sea mucho más solemne. De esta manera, Baquílides canta todas las bondades de sus héroes olímpicos, pues son tanto grandes deportistas como ejemplos de vida correcta y gloriosa; y los himnos homéricos, como ya se observó, estructuran amplias narraciones. Es así como la forma clásica de exaltación hace del himno un género concreto con fórmulas precisas para su composición. Difiere Sologuren por su sensibilidad: vivir la intensidad del más fugaz de los fenómenos es motivo suficiente para loarlo con el canto y ver en él la trascendencia de lo sensible, no como un eco de la fuerza de la Naturaleza sino como su propia realización. Si con alguna forma del amplio repertorio del poeta habría que emparentar la estancia, es con sus haikus, ya que tal amor por los pequeños gestos, los instantes y las manifestaciones sutiles está emparentado con la estética del Japón, de cuya literatura es confeso amante y traductor industrioso. Como apunta Reginald H. Blyth, en el haiku lo 
insignificante, al ser captado por el poeta, se vuelve inolvidable y trascendente (1949: 463).

Para la voz de la estancia basta la mínima impresión de la realidad para maravillarse; y la expresión de esta experiencia, con su composición detallada, contendrá el significado que crea el poema de la entidad externa tratada. De modo que todo el sujeto de alabanza se sintetiza en una sola manifestación, un solo movimiento o vistazo tan potente que ofrece distintas percepciones y hace cantar al yo. $Y$ aun cuando este rasgo puntual fuera más amplio o una condición abstracta, la voz presentará sus realizaciones precisas y sensibles; como sucede con el amor de la estancia final, conceptualizado desde la particularidad de los gestos concretos y las imágenes perceptibles:

Cuerpo a cuerpo,

Hombre y Mujer, se irán quemando en el fuego blanco del amor.

Mano a mano

levantarán el árbol

de la vida,

y su aire y sus pájaros.

Hombre y Mujer,

descubrirán que el mundo

es compañía

y un mismo sol

calentará sus huesos,

y un mismo anhelo

los mantendrá despiertos.

(Sologuren 2004: 155) 
Al igual que en la estancia 3, la experiencia del morir se refigura en movimientos breves y concretos del recibimiento de la muerte. Se trata de una forma específica y personalista de representar la vivencia: mirada en perspectiva que resalta ciertos puntos y silencia otros, modificando el significado de su objeto, creándolo.

Este personalismo de la voz de la estancia es el rasgo que más la aleja de la tradición hímnica clásica, debido a la resemantización a la que somete a las entidades tratadas; mientras que el himno clásico es una práctica social, un canto coral donde se expresa la noción que una comunidad tiene acerca del sujeto alabado. De esta manera, la «Noche» en la estancia 2 no tendrá el significado corriente que la comunidad lingüística le otorga, sino que se transfigura para expresar lo que la voz poética cree que la noche es:

Tú transitas los caminos
de mi corazón, Noche,
y yo asciendo por tus venas
como alborada frágil;
y voy viendo tus aguas
unir raíces, pájaros
caídos, lentas memorias,
insepultos espejos,
náufragos resplandores.

(Sologuren 2004: 145)

Es así que el cliché literario se destierra de Estancias, dándole paso a la plena originalidad; ya que incluso cuando la entidad del poema muestra algún rasgo convencional, la voz presenta su versión propia mediante la figuración y la reacción del yo: 
¡Oh Sueño donde las formas pasan

como por una avenida

alzada en el crepúsculo,

tú me enciendes la sed, los enigmas,

los acallados pasos de mi vida!

(Sologuren 2004: 145)

Quizá la muestra más patente de la fuerza creadora de la visión personal de la voz sea la exaltación de fenómenos que no llamarían la atención en la experiencia real, la fabricación de sujetos de alabanza. Y en esta directriz expresiva encuentra mayor sustento el proceso de condensación de las oraciones. Al respecto, la estancia es un himno que no siempre le canta a aquello que se sabe solemne: la nieve, el árbol, la flor, el hambre o la sed no son temas hímnicos en sí mismos, pero la estancia los recrea como entes dignos de gloria, pues así los siente. Por ejemplo, la acción del hambre es gloriosa por su magnitud universal, por sus efectos sobre toda la humanidad; o el agua simple que asemeja el consuelo espiritual de las palabras santas; así como el árbol se sacraliza al tornarse altar. Los movimientos sencillos de las cosas son transmutados en objetos de maravilla gracias a la metáfora: el simple fluir de un río es transfigurado en criatura magnífica y capaz de expresión propia:

Mueves tus largos miembros

hacia el mar que te aguarda,

musitando palabras

al mar de tu desvelo;

(Sologuren 2004: 152) 
O la sensación táctil de la nieve, invertida a punto de significar algo más trascendente que el solo frío:

Tu ardor, Nieve, en la noche, tu silencioso ardor.

Hay fantasmas que en ti se echan

como amantes en la yerba;

(Sologuren 2004: 147)

Y aun la valoración ética convencional de un significante se ve modificada por lo grandioso de su efecto:

\author{
Yo sé, Muerte, \\ que siempre \\ tienes la puerta \\ abierta. \\ Y tocaré. \\ Y sentirá la sangre \\ su libertad \\ tocar el cielo \\ con relámpagos \\ nuevos.
}

(Sologuren 2004: 146)

Efectivamente, entonces, se concluye que la estancia es una forma poética en la que todos los estratos se conjugan para expresar el sentimiento de maravilla frente a una realidad en principio ajena al yo. En este sentido, la estancia es un himno, pero con un grado poco convencional de perspectiva individual que la distingue de la estructura hímnica común. No es, por tanto, un himno que reafirma las concepciones preexistentes de los diversos fenómenos naturales que moldea, sino 
un vehículo capaz de crear sus propias y espontáneas figuras de alabanza y su propia sensación de lo maravilloso. Ecos, por qué no, aunque toda literatura es ficción, de la vivencia personal de uno de los mayores poetas peruanos del siglo XX. 


\section{Bibliografía}

BLYTH, Reginald H. Haiku. T. II. Tokyo, Hokuseido, 1949.

KAYSER, Wolfgang. Interpretación y análisis de la obra literaria. Madrid, Gredos, 1961.

SILVA-SANTISTEBAN, Ricardo. «Vida continua de Javier Sologuren», en Escrito en el agua. T. II. Lima, Pontificia Universidad Católica del Perú, Ediciones del Rectorado, 2004, págs. 380-391.

SOLOGUREN, Javier. Estancias, en Obras completas. T. I. Lima, Pontificia Universidad Católica del Perú, Ediciones del Rectorado, 2004, págs. 145-155.

. «Hölderlin: "Mitad de la vida"», en Obras completas. T. VII. Lima, Pontificia Universidad Católica del Perú, Ediciones del Rectorado, 2005, págs. 144-150. 